\title{
Possíveis Relações entre o Contexto Histórico e a Recepção do Behaviorismo Radical
}

\author{
Possible Links Between the Historical \\ Context and the Reception of Radical Behaviorism
}

Relaciones entre el Contexto Histórico y la Recepción del Conductismo radical
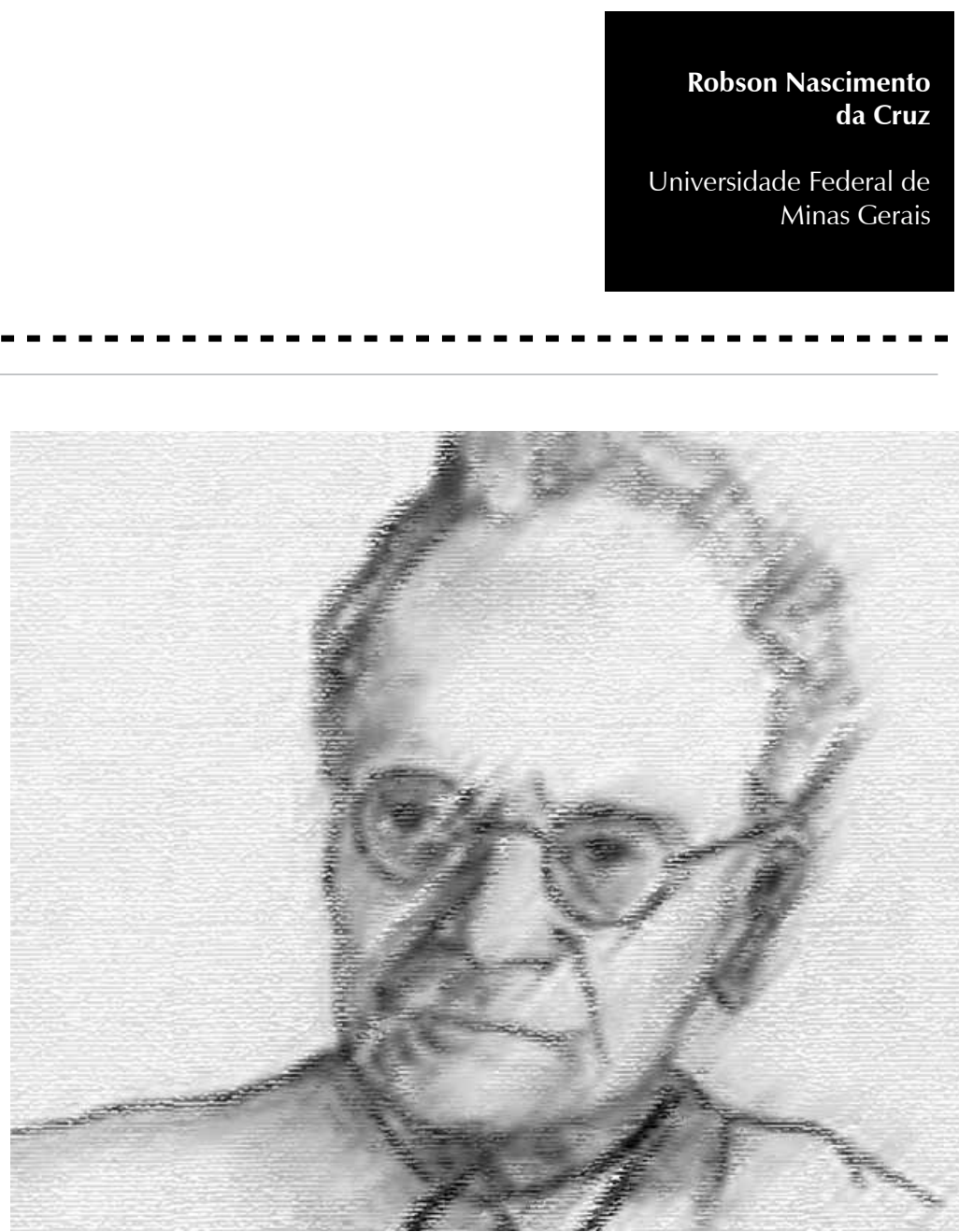
Resumo: O artigo discute a recepção do behaviorismo radical, em especial, na década de 70, e busca relacionar a polêmica em torno de algumas noções skinnerianas acerca da liberdade e da dignidade divulgadas no livro Para Além da Liberdade e Dignidade. Essa discussão foi orientada por três conjuntos de questões: a) a incompatibilidade entre alguns aspectos históricos e a definição behaviorista radical de liberdade e dignidade; b) os problemas em identificar o behaviorismo radical como uma abordagem solidária com os pressupostos de uma ideologia liberalista; c) a linguagem utilizada por Skinner como fonte de problemas. Por fim, são discutidos as limitações e os problemas envolvidos em tentativas de esclarecimentos de possíveis mal-entendidos acerca do behaviorismo radical. Ao mesmo tempo, demonstra-se que a recepção do behaviorismo radical é perpassada por aspectos além daqueles relacionados à validade interna do sistema explicativo skinneriano, e que discordâncias acerca dessa abordagem nem sempre podem ser explicadas como desconhecimento e equívocos sobre a mesma.

Palavras-chave: Behaviorismo radical.B.F. Skinner. História da Psicologia. Análise do Comportamento.

\begin{abstract}
This article discusses the reception of radical behaviorism, especially in the 70's, and tries to link the controversy around some of Skinner's concepts disclosed in his book Beyond Freedom and Dignity. The debate has been guided by three sets of issues: a) the incompatibility between the historical moment and the proposal of radical behaviorist notions of freedom and dignity that explain ways to control the behavior which are not traditionally assumed; b) the problems in identifying the radical behaviorism as compatible with the assumptions of liberalism; c) the language used by Skinner as a source of distortions. Finally, we discuss the limitations and problems involved in the attempts to clarify the possible misunderstandings about radical behaviorism. At the same time, it is shown that the reception of radical behaviorism is pervaded by issues beyond those related to the internal validity of the skinnerian explanatory system, and disagreement about this approach can not always be explained as ignorance and misconceptions about it.
\end{abstract}

Keywords: Radical Behaviorism. B.F. Skinner. History of Psycholgy. Behavior Analysis.

Resumen: El artículo discute la recepción del behaviorismo radical, en especial, en la década de 70, y busca relacionar la polémica en torno a algunas nociones skinnerianas acerca de la libertad y de la dignidad divulgadas en el libro Para Más Allá de la Libertad y Dignidad. Esa discusión fue orientada por tres conjuntos de cuestiones: a) la incompatibilidad entre algunos aspectos históricos y la definición behaviorista radical de libertad y dignidad; b) los problemas en identificar el behaviorismo radical como un abordaje solidario con los presupuestos de una ideología liberalista; c) el lenguaje utilizado por Skinner como fuente de problemas. Por fin, son discutidas las limitaciones y los problemas involucrados en tentativas de esclarecimientos de posibles malentendidos acerca del behaviorismo radical. Al mismo tiempo, se demuestra que la recepción del behaviorismo radical es transcurrida por aspectos además de aquellos relacionados a la validez interna del sistema explicativo skinneriano, y que discordancias acerca de ese abordaje no siempre pueden ser explicadas como desconocimiento y equívocos sobre la misma.

Palabras clave: Conductismo radical. B.F. Skinner. História de la Psicología. Análisis de la Conducta.

Os contextos históricos, sociais e políticos podem ser vistos como fatores imanentes à constituição de qualquer área do saber e, por conseguinte, à própria forma como um tipo de conhecimento é recepcionado em uma determinada sociedade. Isso vale tanto para a arte, a literatura e a filosofia quanto para as teorias científicas. Essas atividades, como quaisquer outras, são produto e produtoras de uma cultura. Mas isso não significa que sejam seu mero reflexo e, portanto, simplesmente reprodutoras ingênuas de sua ideologia ou de seu projeto de sociedade. Em diversos casos, é a contradição e o questionamento de uma cultura que perpassam tais atividades humanas.

Nessa perspectiva, pode-se afirmar que o behaviorismo radical, como filosofia de uma ciência do comportamento, é produto de uma cultura específica; no entanto, isso não quer dizer que seja meramente reflexo de tal cultura. Mas a recepção, tanto popular quanto acadêmica, das formulações do principal representante do behaviorismo radical, B. F. Skinner, é fonte de diversas polêmicas, dentre elas a ideia de ser essa abordagem simples reprodutora de pressupostos que perpassam a 
cultura norte-americana. No presente artigo, a fim de discutir como se dá o surgimento de tais argumentos, traçamos algumas relações entre o contexto histórico social e a recepção do pensamento skinneriano, em especial na década de 70, após a publicação de seu livro mais controverso, Beyond Freedom and Dignity (BFD), já que uma análise, mesmo que incipiente, sobre a recepção desse trabalho parece indicar alguns motivos pelos quais surgiram interpretações tão diversas e polêmicas.

\section{Para além da mera liberdade e dignidade}

BFD foi o décimo livro de Skinner, e o seu segundo livro voltado para o público geral; o primeiro foi Walden Two, de 1948. Sobre o período de elaboração de BFD, que ocorreu entre os anos 1965 e 1970, Skinner (1984a) afirma que, embora já tivesse uma visão geral do que pretendia, a preparação desse livro, em muitos momentos, ocorreu de maneira árdua. Isso aconteceu, segundo ele, não porque tenha sido um livro difícil de escrever e nem porque as ideias expostas fossem totalmente diferentes daquelas já formuladas nos últimos anos, mas por causa da importância do livro, do seu conteúdo e da abrangência de público.

Ainda sobre a história do livro, Skinner (1984a) recorda que o título inicial era Liberdade e Dignidade, mas que alterou o nome a partir da sugestão do editor, que o alertou que esse não parecia ser um bom título, já que os conceitos tradicionais de liberdade e dignidade pareciam não mais fazer parte daquela obra. Com isso, Skinner (1984a, p. 310) afirma que imediatamente sugeriu um novo título: "Além da Liberdade e Dignidade, consciente que eu estava fazendo referência a Nietzsche, Além do Bem e do Mal, e a Freud, Além do Princípio do Prazer". Para Skinner (1984a), o título foi, em grande medida, responsável pelas controvérsias e pelo sucesso do livro, mas, principalmente, pelos inúmeros mal-entendidos. Todavia, Skinner alega que o título não significava que a liberdade e a dignidade não existissem, mas que sua proposta era voltada para mudanças nas práticas culturais que deveriam fazer as pessoas notarem como a chamada liberdade tradicional era limitada. Nesse sentido, propõe uma definição de liberdade e de dignidade para além daquela já aceita e defendida na história da cultura ocidental. Portanto, para Skinner (1971), a definição tradicional de tais noções seria limitada a determinadas condições que impediriam os sujeitos de conhecer os inúmeros determinantes envolvidos no controle dos comportamentos chamados de livres e dignos.

Mas, ao questionar essas noções, Skinner (1984a) afirma que anteviu o possível impacto e as polêmicas que o livro poderia suscitar no público geral, previsão que o levou a experimentar reações emocionais bastante desagradáveis ao longo do percurso de elaboração e de divulgação do livro. Esse aspecto é patente quando observamos o tom da passagem a seguir, que foi escrita por Skinner pouco antes do lançamento de BFD:

\footnotetext{
Estou ficando ansioso. Eu quero que o livro apareça. Este está se tornando o meu livro. O que as pessoas vão dizer? Não há nenhuma chance de que ele vá ser entendido e apreciado por todos. Qual a porcentagem com que posso contar? (Skinner, 1984a, p. 310)
}

A ansiedade descrita por Skinner sobre os efeitos do lançamento de seu livro, realmente, não fora injustificada, tendo em vista, como veremos ainda neste trabalho, as inúmeras polêmicas que essa obra provocou durante os anos seguintes à sua publicação e a marca que deixou na história do behaviorismo radical, em especial pelo fato de definir as noções de liberdade e dignidade como comportamentos controlados por suas consequências, e não como características de um homem livre de qualquer forma de controle. 
Skinner (1984a), na realidade, ressalta que, como cientista, nunca havia considerado as pessoas agentes livres, mas isso não queria dizer, de acordo com ele, que as pessoas fossem controladas de maneira unilateral pelo ambiente. Na verdade, mesmo antes da descoberta do fenômeno comportamental, base de seu sistema explicativo, o condicionamento operante, Skinner (1961) define o comportamento como relação constante e inseparável entre organismo e ambiente, perspectiva fortalecida e contemplada, posteriormente, na definição do comportamento operante como aquele comportamento que produz efeitos no ambiente e é alterado pelas suas consequências. Nessa definição de comportamento, nem organismo, nem ambiente são analisados de maneira independente. Uma consequência lógica desse pressuposto é que tanto aquilo que chamamos de liberdade quanto aquilo que denominamos dignidade são comportamentos, portanto, nunca são independentes de algum tipo de relação de controle com o mundo.

No caso da definição tradicional de liberdade, Skinner (1971) salienta que essa definição seria limitada, porque a "liberdade não se deve à vontade de ser livre, mas a certos processos comportamentais característicos do organismo humano, cujo principal efeito é evitar ou fugir dos chamados aspectos aversivos do ambiente" (p. 37). Com isso, ele explicita que a dita liberdade, como falta de controle, na realidade não existe, porque o comportamento é controlado mesmo quando o indivíduo se diz livre. Mas o autor afirma que a sensação de falta de controle ocorreria porque consequências reforçadoras positivas dificultariam a percepção de tais fontes de controle do comportamento pelos sujeitos, já que, nesses casos, o indivíduo tende a se comportar de forma a não evitar ou a fugir de tais consequências devido ao fato de elas serem responsáveis por efeitos agradáveis no organismo.
A liberdade, portanto, seria um problema gerado por consequências aversivas, porque somente quando alguém está em um contexto em que prevalecem contingências aversivas é que existe a probabilidade de uma pessoa emitir comportamentos de modo a contraatacar, a fugir ou a esquivar-se (sentir-se livre) das consequências produzidas em tais contingências. Nesses casos, a identificação das fontes de controle do comportamento é mais fácil de ser notada, como, por exemplo, na identificação de um governo ditatorial, em uma revolução popular, em uma prisão sem condições mínimas de sobrevivência no caso de uma rebelião de detentos, entre outros possíveis exemplos, que explicitam uma situação aversiva que provoca a fuga, a esquiva ou o contra-ataque. Mas o que Skinner destaca é que, quando prevalecem contingências nas quais predominam reforçadores positivos, é provável que a identificação das fontes de controle seja mais difícil ou que até mesmo se acredite que não haja consequências responsáveis pelo controle do comportamento. Isso ocorre, entre outros motivos, porque consequências reforçadoras positivas não provocam fuga ou ataque por parte das pessoas controladas por tal tipo de consequência. Assim, segundo Skinner (1971):

O comportamento gerado pelo reforço
positivo que apenas retarda consequências
aversivas cria problemas para o defensor da
liberdade. E isso se torna bastante provável,
quando se emprega o processo no controle
intencional, onde o agente de controle
geralmente se beneficia em detrimento
do controlado. Frequentemente poder-
se-ão usar os chamados reforços positivos
condicionados com resultados atrasados.
(p. 30$)$

O exemplo da loteria como forma de controle por reforçamento positivo, citado por Skinner (1971, 1984b), auxilia na compreensão dessa forma de controle do 
Skinner (1971), porém, chama a atenção para o fato de que a "dignidade e o valor de uma pessoa parecem ameaçados ao surgirem indícios de que seu comportamento pode ser atribuído a circunstâncias externas" (p. 43). comportamento dito livre. Nesse exemplo, um governo, em vez de lançar um novo imposto, que traria a insatisfação geral da população e talvez um ataque contra tal medida, simplesmente cria um novo jogo da loteria, que arrecadará a mesma ou maior renda. Dessa maneira, são evitadas reações contrárias ao governo, já que dificilmente alguém alegará que foi obrigado a jogar. Skinner (1971) busca, com esse exemplo, expor formas de controle do comportamento muitas vezes desconsideradas quando estão em vigor contingências de reforçamento positivo. Nessa perspectiva, também afirma que

O sentimento de liberdade converte-se num guia de conduta pouco digno de confiança logo que os supostos agentes de controle recorrem a medidas não-aversivas, como é provável que o façam para evitar os problemas suscitados pela fuga ou ataque dos elementos controlados. Tais medidas não são tão perceptíveis quanto as aversivas, e atuam provavelmente de um modo mais lento, mas não deixam de revestir-se de vantagens óbvias que fomentam a sua aplicação. (p. 32)

Aqui fica claro, como Skinner (1971) destacou várias vezes que seu objetivo nunca foi propor o controle do comportamento, pois este é inerente às relações humanas; o que propõe é a investigação das formas de controle do comportamento, principalmente quando esse controle ocorre em função do benefício de apenas uma das partes em detrimento da outra, seja para a cultura, seja apenas para o indivíduo, a médio e a longo prazos.

Mas o problema, de acordo com Skinner (1971), é que a ideia de controle sempre foi exposta como algo pejorativo e incompatível com a noção de liberdade. Para Skinner, a literatura da liberdade seria a principal divulgadora e defensora dessa concepção que encorajou a fuga e ataque aos agentes de controle, sempre destacando como esses agentes estavam utilizando algum tipo de controle aversivo do comportamento. Dessa maneira, o "controle seria nitidamente o antônimo de liberdade, e, se a liberdade é boa, o controle deverá ser ruim" (Skinner, 1971, p. 36). No entanto, Skinner vai insistir que, embora a literatura da liberdade sinalize várias formas de controle aversivo do comportamento, a escolha que fez do método foi errada ao deixar de lado outras formas de controle do comportamento que não recorrem a medidas aversivas.

Se a liberdade tradicionalmente é um problema gerado somente quando o controle aversivo do comportamento é identificado, o problema da dignidade remete a situações nas quais ocorre a identificação do reforço positivo. Isso porque a dignidade é vista também tradicionalmente como um tipo de comportamento no qual o indivíduo age de forma independente das circunstâncias externas. Nesse caso, respeitando todos os códigos de ética e nunca ferindo a moral e os direitos de outras pessoas, mesmo quando as condições sejam supostamente propícias a isso.

Skinner (1971), porém, chama a atenção para o fato de que a "dignidade e o valor de uma pessoa parecem ameaçados ao surgirem indícios de que seu comportamento pode ser atribuído a circunstâncias externas" (p. 43). Assim, quase que de maneira automática, a identificação de formas de controle do comportamento denominado digno faz com que a pessoa não desperte respeito e admiração pelo que fez. Há nessa concepção a noção de um agente livre e a crença de que algumas pessoas são dignas por natureza, e outros não. Com isso, a "menor ou maior aprovação que alguém recebe curiosamente se relaciona com a visibilidade das causas de seu comportamento. Negamos aplausos quando essas causas são evidentes" (p. 40).

Ainda sobre esse ponto, Skinner (1971) acrescenta que "o grau de louvor que damos é inversamente proporcional à evidência das causas do comportamento. Se não sabemos 
porque uma pessoa age de determinada maneira, atribuímos seu comportamento à própria pessoa" (p. 50); por isso, quanto menor a compreensão acerca dos motivos pelos quais alguém se comportou de maneira digna, maior será a admiração. Desse modo, não é inesperado que nossa admiração, provavelmente, diminua à medida que nosso entendimento aumente. $\mathrm{E}$, naturalmente, tendemos a conceder ao homem autônomo tudo aquilo que não conseguimos explicar.

Nessa perspectiva, louvamos um homem quando ele age de maneira diversa da esperada em um determinado contexto onde supostamente as condições seriam propícias para agir de outra. Por exemplo, quanto menos identificarmos os motivos pelos quais um jovem, inserido em uma condição social em que predominam a criminalidade e a violência, não se envolve com tais atos, maior a tendência a reconhecer esse comportamento como digno e essa dignidade como característica daquele jovem que, por meio de sua força de vontade e esforço individual, não se envolveu com o crime e a violência. Para Skinner (1971), o problema estaria não na caracterização desse comportamento como digno nem, muito menos, no reconhecimento desse comportamento. O problema para ele está no obscurecimento que esse tipo de explicação causa, porque se deixa de considerar que esse comportamento foi produto de uma história única, na qual determinadas consequências produziram esse comportamento, chamado de digno. Skinner também ressalta que a identificação desses determinantes históricos do comportamento, que permitem sua interpretação, é geralmente uma estimulação aversiva para aqueles que acreditam em um agente livre, como se a dignidade da pessoa fosse perdida ao ser explicada.

De maneira geral, a proposta de Skinner é demonstrar que uma análise comportamental possibilita uma explicação alternativa, já que identifica, na história filogenética, na ontogenética e na cultural, os motivos pelos quais uma pessoa emite um comportamento digno, e que, ao contrário das alegações contra isso, identificar esses determinantes na história de vida de uma pessoa não significaria a destruição da sua dignidade, mas sim, uma explicação mais abrangente de tal comportamento e o afastamento de uma explicação essencialista que remeta a causas espúrias do comportamento.

Porém, em um período em que qualquer discurso retomasse questões ligadas ao controle do comportamento, mesmo que essa concepção de controle fosse divergente da concepção tradicional e do questionamento de valores (comportamentos), tão caros à cultura ocidental, como a liberdade e a dignidade, não passaria despercebido. Reacionário, fascista e déspota foram alguns dos rótulos que B. F. Skinner recebeu, principalmente na década de 70, após o lançamento de BFD em 1971 (Rutherford, 2003). A seguir, tentaremos apresentar alguns motivos históricos que levaram a tal recepção.

\section{A hostilidade da década de 70 - a noção de controle comportamental}

Rutherford (2000, 2003, 2004), ao investigar a recepção popular das formulações skinnerianas na cultura americana, entre as décadas de 40 e 70, a partir de revistas e jornais de grande circulação, como a revista Times e o jornal The New York Times, aponta a incompatibilidade entre o contexto histórico e o surgimento de algumas noções centrais da proposta skinneriana para áreas como a educação e a política, incompatibilidade que muito contribuiu para a perpetuação de diversas polêmicas acerca do behaviorismo radical.

Em suas análises, Rutherford (2000, 2003, 2004) destaca as décadas de 60 e 70 como o período de maior repercussão do pensamento de Skinner e, ao mesmo tempo, ressalta 
que, nesse período, valores relacionados à conformidade, à passividade e ao controle da sociedade eram antagônicos a diversos movimentos de contracultura, como o movimento hippie, o feminista e o movimento gay, entre outros. Esses movimentos, que pregavam valores como o humanismo e o anti-institucionalismo, rejeitavam, entre outras coisas, qualquer noção que lembrasse alguma proposta de controle e de ordem social. E foi nesse período que Skinner publicou Beyond Freedom and Dignity, que, no Brasil, recebeu o infeliz título: $O$ Mito da Liberdade. De acordo com Bjork (1993/2006), esse livro pode ser apontado como o grande responsável por tornar a figura de Skinner conhecida pelo público não acadêmico. Com a publicação de BFD, Skinner torna-se figura pública nos EUA e em várias partes do mundo (Skinner, 1984a). Convites para participar de programas de importantes emissoras de televisão nos Estados Unidos e revisões de seu livro nos principais jornais americanos evidenciam sua popularidade naquele período.

Skinner, ao comentar a recepção inicial de sua obra na grande mídia, declara que: "Para Além da Liberdade e Dignidade apareceu na lista dos mais vendidos do New York Times por vinte semanas. Eu me tornei naquele período um embaraçado VIP" (Skinner, 1984a, p. 319). Ao citar uma das primeiras revisões de BFD publicadas no jornal New York Times, ele descreve uma passagem que representa a relevância dada à obra. Nessa revisão, é dito que: "Se você planeja ler algum livro este ano, este é provavelmente o livro que você deveria ler" (p. 318). Mas, como o próprio Skinner sinaliza, isso não significou que as revisões tenham sido todas favoráveis, na realidade:

Outras revisões foram abertamente hostis, e parecia que assim que os revisores liam a revisão de outros revisores, tornavam suas revisões cada vez mais agressivas. Uma revisão foi ilustrada com o desenho de um rato que tinha meu rosto caricaturado (isso foi de certo modo um consolo, porque, em uma edição do Sunday Times, tinha aparecido um pombo com minha cabeça, mas a cabeça de Darwin também tinha aparecido em um macaco). (Skinner, 1984a, p. 318)

Dentre as diversas revisões publicadas, Skinner cita a revisão de Chomsky (1971) como a que, provavelmente, mais o desagradou, lembrando que essa seria a segunda revisão publicada por Chomsky; a primeira foi a polêmica e impactante revisão de Verbal Behavior, em 1959 (Chomsky, 1959; ViruésOrtega, 2006). A revisão de BFD por Chomsky foi publicada no The New York Review of Books, com o título The Case Against B. F. Skinner, e apresentou, como pode ser observado na passagem abaixo, o mesmo tom de ataque da conhecida revisão de 1959:

Em suas especulações sobre o comportamento humano, que devem ser claramente distinguidos de suas investigações experimentais do comportamento condicionado, B. F. Skinner oferece uma versão particular da teoria da maleabilidade humana. A recepção pública de seu trabalho é uma questão de algum interesse. Skinner foi condenado como um defensor do pensamento totalitário e louvado pela sua defesa de um ambiente social bem gerido. Ele é acusado de imoralidade e elogiado como um porta-voz da ciência e da racionalidade em assuntos humanos. Ele parece estar atacando valores humanos fundamentais, exigindo controle no lugar de defesa da liberdade e dignidade. Parece existir algo escandaloso nisso, e, uma vez que Skinner invoca a autoridade da ciência, alguns críticos condenam a própria ciência, ou a "visão científica do homem," para apoiar essas conclusões, enquanto outros garantem-nos que a ciência vai "vencer" sobre o misticismo e a crença irracional. (Chomsky, 1971, p. 18)

Embora Chomsky cite as críticas em terceira pessoa, assim como em sua crítica ao livro Verbal Behavior, evidentemente tece e está do lado daqueles que apresentam críticas negativas ao livro. Ao comentar tal revisão, Skinner (1984a) argumenta que Chomsky 
o retratou como um homem que queria controlar as pessoas, "um ditador, um fascista, um totalitarista, o que foi um mal-entendido de todo meu trabalho, assim como em Para Além da Liberdade e Dignidade (p. 321). O principal mal- entendido estaria, para Skinner (1984a), pautado na reprodução da crítica que alegava que ele estava propondo o controle do comportamento, mas os críticos se esqueciam de notar que a noção de controle em seu sistema explicativo não correspondia a controle unilateral, mas sim, a toda relação estabelecida por qualquer organismo com o ambiente.

No Brasil, o reconhecimento da figura de Skinner pode ser constatado em duas edições da revista Veja, em 1974 e 1983, em que o autor concede duas entrevistas apresentadas nas páginas amarelas dessa revista. Os títulos das entrevistas, Um pensamento polêmico e Estado de alerta máximo, realçam o tom dado à divulgação de suas ideias. A forma como o trabalho de Skinner é citado em tais entrevistas pode ser notado na passagem abaixo, que é parte da introdução de sua entrevista de 1974:

já com ampla reputação, instalado na cátedra de psicologia Edgar Pierce da Universidade de Harvard, Skinner escreveria o mais debatido de seus trabalhos: "Beyond Freedom and Dignity" (1972). Desafiadoramente, o título propunha justamente o que os críticos de Skinner haviam denunciado como o resultado mais nocivo de suas teorias: um mundo (feliz, segundo Skinner, mas de pesadelo, segundo seus críticos) de homens controlados por manipulações psicológicas, "além da liberdade e da dignidade". Embora aclamada em algumas publicações especializadas, a obra causou incontrolável revolta e uma avalancha de criticas esmagadoras - especialmente em um longo ensaio de Noam Chomsky, um dos mais importantes pensadores americanos da atualidade. (Veja, 1974, p. 3)
Ao tentar explicitar os prováveis motivos dessas reações tão violentas ao livro de Skinner, Rutherford (2003) relembra outros fatos históricos que facilitaram interpretações tão negativas. O período pós-guerra, marcado por uma quase eminente guerra nuclear, acompanhado de uma Guerra Fria entre EUA e a ex-União Soviética, a guerra do Vietnã e a insatisfação da população americana devido ao grande número de soldados americanos mortos, além dos inúmeros ataques e questionamentos àquelas que pareciam ser a solução dos problemas humanos - a ciência e a tecnologia. Dessa maneira, "a visão skinneriana para a reforma cultural e os valores que guiam BFD colidiram com a atmosfera antitecnocrata e anti-intelectual do início dos anos setenta. Assim, 1971 foi particularmente um momento histórico inóspito para o surgimento desse livro" (Rutherford, 2003, p. 13).

De modo similar, no caso dos contextos brasileiro e latino-americano, é a partir das décadas de 60 e 70 que eclodem as principais críticas à hegemonia de teorias psicológicas, sociológicas e políticas, entre outras, advindas, principalmente, dos EUA, e adotadas em inúmeros países latino-americanos sem uma avaliação mínima das implicações de seus usos. De acordo com Fernandes (1989/2000), tais críticas, em geral, destacavam a função ideológica que perpassava essas teorias. Ainda de acordo com a autora, é nesse período que ocorre o ápice da contestação de uma parte significativa da comunidade científica brasileira, principalmente nas ciências humanas, ao regime militar e à forma como a ciência brasileira se voltava para as questões nacionais. Dessa forma, um livro que foi desastrosamente traduzido para o português com o título O Mito da Liberdade permitiu uma interpretação bastante negativa, como se o autor estivesse argumentando que a liberdade e a dignidade não existissem. Segundo Todorov (2003), com esse título, no Brasil, o livro foi rotulado antes de ser lido, e o nome de Skinner foi associado à política de direita. 
Para além da Liberdade e Dignidade (Skinner, 1971) é, na minha opinião, um título terrivelmente enganoso, mesmo em inglês. Ele permite a interpretação que o autor está tratando da liberdade e da dignidade de forma menos positiva, senão de modo pejorativo. A tradução para o português foi um desastre: O Mito da Liberdade. Com esse título, um esquerdista vai odiar o livro antes de lê-lo, e isso foi o que aconteceu com Skinner no Brasil. (Todorov, 2003, p. 343)

Sabe-se que as críticas ao uso de teorias importadas, nesse período, não são de todo infundadas e sem justificativas válidas. Basta lembrar a situação política e econômica dos países latino-americanos nesse período, que estavam, em sua maioria, sob o comando de ditaduras militares, e que contavam com apoio político e econômico dos EUA para a manutenção desse regime (Rapoport \& Laufer, 2000). Presume-se que esse fato e seus desdobramentos na situação social desses países tenham sido condição aversiva suficiente para provocar respostas tão negativas a teorias advindas do contexto norte-americano, em especial, as teorias do comportamento. No entanto, questionase que o simples fato de uma teoria ser americana não representa motivo suficiente para ser criticada sem ao menos ter sido avaliada; esse comportamento ainda é corrente, em especial nas ciências humanas, devido, provavelmente, ao excesso de fiscalização ideológica herdada, em alguma medida, desse período.

Tendo em vista essas questões, argumenta-se que rotular o behaviorismo radical como um tipo de produto eminentemente americano e, por conseguinte, reprodutor da ideologia que perpassa essa cultura é algo comum. E é óbvio que seria ingenuidade afirmar que as formulações skinnerianas não são, em determinado nível, fruto de tal cultura. Entretanto, deve-se considerar que o próprio Skinner criticou duramente os padrões de comportamento estabelecidos por essa cultura e pela cultura ocidental de modo geral. É nítida essa posição de Skinner, como um ferrenho crítico do sistema capitalista e de seus principais pressupostos, como o liberalismo, já na década de 1940 e ao longo de toda a sua carreira, em diversos trabalhos (Skinner, 1948, 1987).

\section{Behaviorismo radical $\mathrm{x}$ liberalismo}

Dittrich (2004), ao investigar a posição do behaviorismo radical no campo da Filosofia política a partir de uma análise comparativa entre behaviorismo radical e liberalismo, mostra a impossibilidade de essa abordagem ser conivente com essa posição. Em sua análise, Dittrich (2004) destaca que, embora haja diversas variações daquilo que seja liberalismo dentro do campo da Filosofia política, pode-se afirmar que essa filosofia, em geral, tem como foco as noções de liberdade e individualismo, sendo a liberdade entendida como a ausência de coerção, e o individualismo, como a capacidade de o indivíduo agir em função de seus próprios desejos, sem a interferência de fatores externos, o que leva a uma ênfase na responsabilidade individual. A partir disso, Dittrich sugere que:

Os pressupostos fundamentais do liberalismo são marcadamente diferentes daqueles presentes no behaviorismo radical. $\mathrm{O}$ individualismo, por exemplo, opõe-se diretamente às concepções ontológicas, éticas e políticas de Skinner. As ações de um indivíduo não podem ser compreendidas à parte de seu ambiente social, e as culturas são o parâmetro fundamental do planejamento ético e político. Nesse sentido, o liberalismo incorre no mesmo erro presente na filosofia anarquista: ao concentrar-se, sobretudo, em concepções negativas de liberdade, ignora o controle exercido pelas contingências de reforçamento positivo (ou, ao menos, trata-o de forma superficial). Assim, afirmase que o indivíduo é "livre" para escolher e perseguir seus próprios objetivos - quando, para o behaviorismo radical, tais "objetivos" são parte das conseqüências que controlam comportamento que os persegue. (Dittrich, 2004, p. 257) 
Ainda no que se refere às propostas skinnerianas como produto eminentemente americano, Bjork (1993/2006) argumenta que o livro mais polêmico de Skinner, BFD, parece ter causado controvérsias justamente por ser contrário à concepção americana de liberdade. Para ele, a ideia central do livro questionava uma das principais, senão a principal crença americana - a busca incessante pela liberdade individual. Para Bjork, Skinner evidencia que a concepção de liberdade defendida pela cultura americana, além de ser limitada, seria prejudicial para a cultura como um todo, porque não demonstrava as formas de controle vigentes quando as pessoas se dizem (se sentem) livres. Dessa maneira, "o livro desafiou aquilo que os americanos mais acreditavam ser americano" (Bjork, 1993/2006, p. 193), ou seja, Skinner criticou um dos principais, senão o principal pilar da ideologia daquele país e, ao mesmo tempo, revelou um tipo de controle do comportamento que é mascarado pelo discurso liberalista.

Chauí (1980/2004), ao definir ideologia, indica, entre outras coisas, que essa pode ser considerada uma forma de ocultamento da realidade social, na qual, em geral, uma classe dominante reproduz ideias e representações que serão difundidas de maneira a assegurar seu poder econômico, social e político, e que esse ocultamento tem como função "esconder dos homens o modo real como suas relações sociais foram produzidas e a origem das formas sociais de exploração econômica e de dominação política" (p. 23). Nesse sentido, a ideologia liberalista mascararia uma realidade social na qual os homens, em diversas situações, seriam controlados, mesmo quando se dissessem livres. Ao examinar, como já citado, que um dos principais objetivos de Skinner em BFD e em outras publicações é explicitar como todas as relações entre os homens são estabelecidas por meio de relações de controle, inclusive aquelas nas quais as pessoas acreditam que não são controladas por agências de controle como o governo, a educação e a religião, torna-se possível afirmar que os pressupostos do behaviorismo radical são inconciliáveis com os de uma ideologia liberalista que prima pela ideia de liberdade como ausência de controle de qualquer espécie.

\section{A linguagem behaviorista radical e o estudo do controle aversivo}

Carrara (1998/2005), ao discutir as temáticas e os contextos relevantes dos quais emergem as críticas ao behaviorismo radical, destaca igualmente a área ético-social como uma das principais geradoras de questões polêmicas e controvérsias. Dando destaque às incompreensões relacionadas à noção de controle comportamental, Carrara, antes de apontar os fatores externos relacionados a esse problema, indica um fator interno ao behaviorismo radical como facilitador de recepções negativas ao pensamento skinneriano. Para ser mais específico, Carrara ressalta o comportamento de Skinner como um possível propiciador de tais problemas.

De acordo com Carrara, embora Skinner tenha expressado diversas vezes que a ideia de controle esteja vinculada à determinação do comportamento e não à manipulação unilateral, ele parece não ter feito grandes esforços para esclarecer isso. Nessa mesma linha de raciocínio, Bjork (1993/2006) alega que, no episódio que envolve BFD, Skinner comete o erro de escrever um livro para o público geral utilizando expressões conhecidas apenas por praticantes ou estudiosos da teoria operante. $\mathrm{O}$ uso excessivo de expressões técnicas, como controle, reforço positivo e negativo e contingências de reforçamento tornou muitas de suas proposições difíceis de serem compreendidas e facilitou interpretações equivocadas para uma audiência não comportamentalista. Ainda de acordo com Carrara (1998/2005),

Os esclarecimentos de Skinner constituíram artigos eminentemente técnicos, de modo que não foram sempre bem absorvidos, 
especialmente pela crítica leiga ou que, ao menos, não tivesse boa familiaridade com o rol de pressupostos da abordagem. Nas suas publicações para o grande público, Skinner efetivamente não se esforçou para esclarecer o conceito de controle. De certo modo, usou frequentemente uma linguagem provocativa, o que aumentou a intensidade da crítica. Nas suas duas mais controvertidas obras (Walden Two - uma novela em que nem poderia (pela época) e à qual nem caberia ser esclarecedora a respeito - e Beyond Freedom and Dignity) Skinner sempre acentuou arestas nessa área conceitual. (p. 280)

Como já citado, as recepções da noção de controle sugerem que Skinner defende e preconiza a utilização do controle de forma unilateral, ao mesmo tempo em que sugerem que, nessa proposta, seria o behaviorista radical o controlador. Segundo Carrara, ainda acerca dessa noção, há uma constante divulgação infundada de que Skinner recomenda o controle aversivo na resolução de problemas comportamentais.

Carrara esclarece que é preciso diferenciar o estudo de contingências aversivas da utilização de controle aversivo. Estudar contingências aversivas é algo que Skinner e outros diversos behavioristas radicais fizeram, e ainda fazem, e é absolutamente justificável estudar esse fenômeno para compreender como funciona esse tipo de controle tão comum em nossa cultura. Mas isso nada tem a ver com a recomendação dessa forma de controle, e Skinner nunca aconselhou sua utilização. Na realidade, demonstrou, em várias oportunidades, os efeitos nocivos do uso de tal controle, algo evidente, por exemplo, nas suas formulações sobre a educação (Skinner, 1968/1972).

As discussões apresentadas até o momento, embora breves, não deixam dúvidas de que o contexto histórico, o político e o social privilegiaram uma interpretação hostil do pensamento skinneriano, que tem repercussões até os dias atuais, já que muitos argumentos críticos ainda são pautados nesses critérios para interpretar o behaviorismo radical. Entre os prováveis efeitos desse problema, pode-se dizer que houve a formulação de uma regra que não corresponde a diversas formulações skinnerianas, algo que prejudicou e ainda prejudica o contato direto com suas ideias. Assim, como sugerido por Todorov (2003), é provável que um esquerdista tenda a rejeitar o pensamento skinneriano antes mesmo de entrar em contato com suas formulações.

Poder-se-ia pensar nesses problemas como regras que controlam comportamentos de distorção do behaviorismo radical, tendo em vista que comportamentos governados por regras são comportamentos que estão sob o controle de estímulos verbais, que especificam uma contingência e que funcionam de forma a tornar a emissão do comportamento mais econômica. Em outras palavras, a regra possibilita ao ouvinte uma espécie de atalho, que não exige a emissão de diversos comportamentos, nesse caso - ler, discutir e tentar compreender, de maneira mais detalhada e crítica, uma teoria. Isso acaba por facilitar a manutenção e a aquisição de comportamentos de distorção, em suma, adquirir o comportamento de distorcer uma teoria é mais fácil do que adquirir o comportamento de compreender uma teoria de forma crítica. A consequência dessa situação é óbvia, mesmo quem nunca leu diretamente qualquer trabalho de Skinner, nas diversas áreas do conhecimento, tem, provavelmente, uma visão e uma opinião caricaturadas de seu pensamento.

Mas aqui é preciso uma ressalva, porque uma conclusão aparente sobre as questões colocadas até agora poderia ser que a oposição ao pensamento skinneriano seria produto somente de equívocos acerca de seu pensamento. Entretanto, autores como Miguel e Nakamura (1996), Miraldo (1985) e Rodrigues (2002), ao investigarem os fatores que propiciam oposição ao behaviorismo radical, localizaram, tanto na literatura quanto em entrevistas com psicólogos e estudantes de Psicologia, dados que apontam uma oposição ao behaviorismo radical não relacionada ao desconhecimento dessa abordagem, 
mas à discordância de ordem ideológica, epistemológica e pessoal.

Carrara (1998/2005) e Banaco (1997) também levantam outras hipóteses para a oposição ao behaviorismo radical. Para esses autores, em alguma medida, o próprio comportamento da comunidade behaviorista estaria entre as causas pelas quais essa abordagem é continuamente alvo de ataques e críticas, muitas vezes mal formuladas. Carrara (1998/2005) diz, por exemplo, que "ainda que sem generalizar, pode-se dizer que as respostas dos behavioristas têm priorizado o sentido quase exclusivo de tentar rechaçar toda e qualquer análise que aponte características negativas na abordagem" (p. 13). Já Banaco salienta que, muitas vezes, os próprios behavioristas, ao não terem suas práticas reconhecidas e serem, em consequência, desprovidas de reforçadores, começaram a atacar os que os atacavam, recusando tudo o que se assemelhasse a mentalismo. Esses autores indicam a necessidade de uma crítica interna à comunidade behaviorista na explicação das causas de sua rejeição. Contudo, todos são unânimes em afirmar que existe a predominância de mal-entendidos e de críticas infundadas.

Com essa discussão inicial, é possível supor que parece haver um acordo intersubjetivo - uma opinião dominante sobre o behaviorismo radical e a figura de B. F. Skinner. De acordo com Demo (1985), a intersubjetividade pode ser entendida como um efeito dos condicionamentos sociais, o que, no entanto, não é suficiente para ser usado como argumento válido para a análise crítica de uma teoria. Por essa razão, o argumento pautado na intersubjetividade tem, em geral, seus critérios advindos de um contexto externo, que foi construído em volta da questão e não a partir dela, algo que se presume possa ter ocorrido em alguma medida na história do behaviorismo radical.

Em vista disso, pode-se dizer que uma crítica coerente necessita ser apoiada em uma análise cuidadosa, partindo minimamente da própria teoria, e não da mera opinião externa. Com isso, não se quer afirmar que o crítico de uma teoria deva ser um adepto ou um estudioso da área, mas que deve ter o mínimo de conhecimento sobre as questões internas da disciplina que pretende criticar para que a crítica possa ter o mínimo de crédito e, o mais importante, possa ter a devida importância para a construção do conhecimento.

\section{Considerações finais}

Os exemplos citados neste trabalho, embora incipientes, mostram que o contexto histórico social está diretamente relacionado à recepção de uma teoria. No caso do behaviorismo radical, esse aspecto é bastante nítido, em especial, com a publicação de BFD, na década de 70. A polêmica em torno da publicação desse livro sugere certa contradição, isso porque, nos Estados Unidos, Skinner foi criticado principalmente por atacar os principais pressupostos do liberalismo, a ideia de individualismo e a noção de liberdade como ausência total de controle; já no contexto latino-americano, pode-se pensar que as críticas se voltam para a ideia de ser sua teoria mera reprodutora da ideologia americana e direcionada para o controle e a manipulação unilateral do comportamento.

A apresentação desses aspectos não significa a inexistência de problemas internos à própria teoria e comunidade científica; sobre isso, destacamos, brevemente, a possibilidade de Skinner ter facilitado as apreciações negativas acerca de seu trabalho. Isso é indicado por Carrara (1998/2005) e Bjork (1993/2006), que mostram que Skinner, ao recorrer a uma linguagem provocativa e bastante técnica em obras que eram destinadas a um público geral, como foi o caso de BFD, pode ter facilitado o surgimento de concepções polêmicas, especialmente em relação à noção de controle comportamental.

Uma possível maneira de lidar com os problemas apontados no presente artigo seria analisar a função que as críticas direcionadas ao behaviorismo radical desempenham em nível individual e social nos contextos 
onde essas críticas são emitidas, trabalho que já vem sendo realizado por alguns pesquisadores (Banaco, 1997; Carrara, 1998/2005; Miraldo, 1985; Miguel \& Nakamura, 1996; Rodrigues, 1999, 2002, 2003). Portanto, é preciso estar atento às consequências sofridas tanto por quem emite essas críticas quanto por quem as recebe. Trata-se, portanto, de analisar o efeito comportamental dessas críticas, que podem ter inúmeras funções.

Expor de forma mais clara para o público neófito e leigo os aspectos conceituais, históricos e epistemológicos do behaviorismo radical seria uma forma de amenizar esses problemas. Entretanto, não se pode pensar que isso seja suficiente para diminuir as incompreensões acerca de teorias filosóficas e científicas, já que esse tipo de problema não pode ser reduzido e explicado somente como produto de incompreensões de cunho conceitual e histórico.

Dessa forma, ressalta-se que não houve, aqui, a ilusão e nem a proposta de que o esclarecimento seja suficiente para a compreensão do behaviorismo radical e, por conseguinte, para a sua aceitação e/ou adoção; não é essa a proposta, até porque o fato de se aceitar ou não uma teoria ou até mesmo de se adotá-la como orientação teórica não vem apenas da coerência interna de um modelo científico, mas de questões de ordem estética, econômica, política, pessoal e de status social, entre outras, que podem estar relacionadas a essa aceitação.

Kuhn (1962/2006), por exemplo, sugere que os cientistas muitas vezes são treinados para considerar uma teoria errada historicamente em função da comunidade científica em que estão inseridos. Ao mesmo tempo, argumentos que a comunidade na qual o cientista está inserido teria uma versão mais sofisticada e necessariamente mais evoluída da ciência são extremamente reforçados na iniciação do cientista. Hagstrom (1979) demonstra como os cientistas, muitas vezes, são levados a escolher determinadas áreas, teorias e temas de pesquisa devido ao reconhecimento social que thes proporcionarão, o que faz com que, ao mesmo tempo, rechacem áreas supostamente ultrapassadas e/ou polêmicas na ciência, porque diminuiriam as suas chances de sucesso. Bourdieu (1983), também ao analisar os fatores que afetam as decisões e as posturas dos cientistas, apresenta a noção de campo científico como um campo no qual muitas das ações dos cientistas são orientadas por mecanismos semelhantes àqueles da economia de mercado. Dessa maneira, os cientistas criariam estratégias para vencer a concorrência, para acumular capital e por oportunidades de mercado que aumentam as chances de lucro. Em todos esses casos, o desmerecimento, não necessariamente pautado em critérios racionais, de uma área científica seria prática corrente de toda comunidade científica que busca sobressairse.

Mesmo sem nos aprofundarmos nessas questões, elas possibilitam, no mínimo, pensar que a manutenção de críticas ao behaviorismo radical seja também produto de posturas como as apontadas por Bourdieu (1983), Hagstrom (1979) e Kuhn (1962/2006). Ao mesmo tempo, é também de se presumir que a comunidade behaviorista faça parte desse campo complexo de funcionamento da comunidade científica, em que questões, além daquelas ditas científicas, afetam e fazem parte da organização da ciência.

Por fim, salienta-se que essa discussão teve também como objetivo contribuir para que iniciantes e iniciados, tanto na ciência psicológica quanto em outras áreas, tenham uma visão mais ampla e crítica do behaviorismo radical, e que essa visão sirva como referência crítica para futuras escolhas e discussões de como possíveis interpretações de uma área do conhecimento podem ser eivadas por questões que vão além da própria disciplina, das quais nem seus críticos, nem seus adeptos, muitas vezes, têm consciência, considerandose, por isso, isentos de responsabilidade. 


\section{Robson Nascimento da Cruz}

Doutorando em Psicologia, Universidade Federal de Minas Gerais, Belo Horizonte, MG - Brasil.

\section{Endereço para envio de correspondência:}

Rua Agenor Alves, no 68, Nazaré. Belo Horizonte, MG - Brasil - CEP 31 990-040.

E-mail: robsonncruz@ig.com.br

Recebido 28/12/2008, 1a Reformulação 25/11/2009, Aprovado 28/01/2010.

\section{Referências}

Banaco, R. A. (1997). Podemos nos beneficiar das descobertas da ciência do comportamento? In R. A. Banaco (Org.), Sobre comportamento e cognição: aspectos teóricos, metodológicos e de formação em análise do comportamento e terapia cognitiva (pp. 543-555). Santo André, SP: ARBytes.

Bjork, D. W. (2006). B. F. Skinner: A life. New York: Sheridan Books. (Trabalho original publicado em 1993)

Bordieu, P. (1983). O ca[mpo científico. In R. Ortiz (Org.), Pierre Bourdieu: sociologia (pp. 122-155). São Paulo: Ática.

Carrara, K. (2005). Behaviorismo radical: crítica e metacrítica. Marília, SP: Ed. da UNESP. (Trabalho original publicado em 1998)

Chauí, M. (2004). O que é ideologia? São Paulo: Brasiliense. (Trabalho original publicado em 1980)

Chomsky, N. (1959). A review of B. F. Skinner's. Verbal Behavior. Language, 35(1), 26-58.

Chomsky, N. (1971, 30 de dezembro). The case against B. F. Skinner. The New York Review of Books, 17, 18-24.

Demo, P. (1985). Introdução à metodologia da ciência. São Paulo: Atlas.

Dittrich, A. (2004). Behaviorismo radical, ética e política: aspectos teóricos do compromisso social. Tese de Doutorado, Universidade Federal de São Carlos, São Carlos, SP.

Fernandes, A. M. (2000). A construção da ciência no Brasil e a SBPC. Brasília, DF: Ed. da UnB. (Trabalho original publicada em 1989)

Hagstrom, W. (1979). O controle social dos cientistas. In R. K. Merton \& J. D. de Deu. A crítica da ciência: sociologia e ideologia da ciência (pp. 81-107). Rio de Janeiro: Zahar.

Kuhn, T. S. (2006). A estrutura das revoluções científicas. São Paulo: Perspectiva. (Trabalho original publicado em 1962)

Miguel, C., \& Nakamura, M. (1996). A concepção do aluno de psicologia da PUC - SP sobre o behaviorismo radical e seus possíveis determinantes. São Paulo: Programa de Iniciação Científica da PUC-SP.

Miraldo, C. M. V. (1985). Conhecimento e crenças de estudantes de psicologia acerca da análise experimental do comportamento. Dissertação de Mestrado, Instituto de Psicologia, Universidade de São Paulo, São Paulo.

Rapoport, M., \& Laufer, R. (2000). Os Estados Unidos diante do Brasil e da Argentina: os golpes militares na década de 1960. Revista Brasileira de Política Internacional, 43(1), 69-98.

Rodrigues, M. E. (1999). Algumas concepções de profissionais de educação sobre behaviorismo. In Sobre comportamento e cognição: psicologia comportamental e cognitiva - da reflexão teórica à diversidade na aplicação (pp. 240-250). Santo André, SP: ARBytes.
Rodrigues, M. E. (2002). Behaviorismo radical: mitos e discordâncias. Cascavel, PR: Edunioeste.

Rodrigues, M. E. (2003). Identificação de fatores relacionados à oposição ao behaviorismo radical. In Sobre comportamento e cognição: a história e os avanços, a seleção por conseqüências em ação (pp. 179-194). Santo André, SP: ESETec.

Rutherford, A. (2000). Radical behaviorism and psychology's public: B. F. Skinner in the popular press, 1934-1990. History of Psychology, 3, 371-395.

Rutherford, A. (2003). B. F. Skinner's technology of behavior in American life: From consumer culture to counter culture. Journal of History of the Behavioral Sciences, 39, 1-23.

Rutherford, A. (2004). A "visible scientist": B. F. Skinner writes for the popular press. The European Journal of Behavior Analysis, 5, 109-120.

Skinner, B. F. (1948). Walden two. New York: MacMillan.

Skinner, B. F. (1961). The concept of the reflex in the description of behavior. In B. F Skinner (Ed.), Cumulative record: A selection of papers (pp. 319-346). New York: AppletonCentury-Crofts. (Trabalho original publicado em 1931)

Skinner, B. F. (1971). Beyond freedom and dignity. New York: Alfred A. Knopf.

Skinner, B. F. (1972). Tecnologia do ensino. São Paulo: Herder. (Trabalho original publicado em 1968)

Skinner, B. F. (1974, setembro). Um pensamento polêmico. (Entrevista). Veja, pp. 3-6.

Skinner, B. F. (1983, junho). Estado de alerta máximo (Entrevista). Veja, pp. 3-6.

Skinner, B. F. (1984a). A matter of consequences: Part three of an autobiography. New York: New York University Press.

Skinner, B. F. (1984b). Contingências do reforço: uma análise teórica. In Os pensadores (Vol. 2). São Paulo: Abril Cultural. (Trabalho original publicado em 1969)

Skinner, B. F. (1987). What is wrong with daily life in the western world? In B. F. Skinner, Upon further reflection. New Jersey: Englewood Clifs.

Skinner, B. F. (2002). Sobre o behaviorismo. São Paulo: Cultrix. (Trabalho original publicado em 1974)

Todorov, J. C. (2003). Science and human behavior translated into Portuguese: ciência e comportamento humano. Journal of the Experimental Analysis of Behavior, 80(3), 341-343.

Virués-Ortega, J. (2006). The case against B. F. Skinner 45 years later: An encounter with N. Chomsky. The Behavior Analyst, 29, 243-251. 